\title{
O pensamento selvagem de michel leiris'
}

\author{
A ÁFRICA FANTASMA, \\ de Michel Leiris. São Paulo: CosacNaify, 2007
}

\section{Luís FELIPE SOBRAL}

\begin{abstract}
[1] Este texto foi desenvolvido ao longo do curso História e Teorias da Antropologia I", ministrado no PPGAS da Unicamp pela profa. dra. Suely Kofes, no primeiro semestre de 2008. A ela e aos meus colegas agradeço pelo debate ímpar; à minha orientadora, profa. dra. Heloísa Pontes, pela leitura e sugestões sempre precisas e estimulantes.
\end{abstract}

[2] Melville, Herman.Moby Dick, ou $A$ baleia, trad.de Irene Hirsch. São Paulo: CosacNaify, 2008, p. 499 .

[3] Calvino, Italo. Por que ler os clássicos.São Paulo:Companhia das Letras, 2007, p. 15.

[4]Leiris, Michel. A África fantasma, trad.André Pinto Pacheco, apresentação Fernanda Arêas Peixoto. São Paulo: CosacNaify, 2007. Devo sublinhar que se trata do terceiro título de autoria de Leiris traduzido por tal editora; os outros dois são: Espelho da tauromaquia, 2001, eA idade viril: precedido por Da literatura como tauromaquia, 2003. Ambos são inéditos no Brasil, apesar de, originalmente, terem sido publicados em 1938 e 1939 , respectivamente.

[5]Jamin, Jean. "Présentation de L'Afrique fantôme". In: Leiris, M. Miroir de l'Afrique. Paris: Gallimard, 1996, pp. 65-85, p. 65.

[6] Peixoto, Fernanda A. "A viagem comovocação - Antropologia e literatura na obra de Michel Leiris". In: Leiris, M. A África fantasma, op. cit., pp. 19-33, p. 19. Outro artigo de interesse, da mesma autora, é "O nativo e o narrativo - Os
[...] essa tatuagem fora obra de um finado profeta e vidente de sua ilha, o qual, mediante tais sinais hieroglificos, escrevera em seu corpo uma teoria completa dos céus e da terra e um tratado místico sobre a arte de alcançar a verdade; de modo que Queequeg, por seu próprio corpo, era um enigma a ser decifrado; uma maravilhosa obra em um volume; mas cujos mistérios nem mesmo ele próprio podia ler, ainda que seu próprio coração pulsante batesse contra eles; e esses mistérios estivessem, portanto, destinados a se desfazer no pó do pergaminho vivo em que estavam inscritos e ficar sem solução até o fim. E deve ter sido esse pensamento que sugeriu a Ahab aquela sua furiosa exclamação, quando certa manhã ele retornava da visita ao pobre Queequeg - "Oh, diabólica tentação dos deuses!".

Herman Melville,Moby Dick, ou Abaleia

No breve ensaio em que explora os múltiplos sentidos da categoria "clássico", Italo Calvino apresenta, entre outras, a seguinte formulação: "É clássico aquilo que persiste como rumor mesmo onde predomina a atualidade mais incompatível"3.

Através deste moteé que gostaria de abordar a primeira tradução brasileira de AÁfrica fantasma, de Michel Leiris ${ }^{4}$ — publicado originalmente em 1934 pela parisiense Gallimard, editora na qual, desde então, recebeu seis edições em diferentes coleções ${ }^{5}$. Obra inclassificável, toma forma "[...] como uma colagem de fragmentos que se sucedem ao sabor da cronologia, fio a costurar observações etnográficas, idéias e fantasias" 6 . Não encontra, portanto, um lugar para residir no cânone antropológico modernista, de cuja história, contudo, faz parte, uma vez que esta, 
ao incluir certos títulos de forma pertinente, acaba por excluir outros de modo revelador. Todavia, o mais importante é que A África fantasma enfrenta, a seu modo muito peculiar, a principal questão da antropologia modernista: a busca intransigente pelo real. "Tese: é pela subjetividade (levada a seu paroxismo) que se alcança a objetividade"7, aponta Leiris em uma época na qual a vivência pessoal em campo estava confinada aos prefácios e posfácios das etnografias. Enfim, excluído do cânone, mas não de sua época. Incompatível com a antropologia do século XXI, na qual averdade, se não foi dissolvida, encontra-se em xeque; mas também na qual, não obstante, o debate sobre a presença do autor em seu próprio texto - ou seja, sua subjetividade - assume caráter incontornável.Um clássico, por conseguinte, de acordo com a acepção de Calvino.

\section{II}

A África fantasma é o diário de viagem de Michel Leiris, secretárioarquivista da missão Dacar-Djibuti, expedição lingüística e etnográfica que empreendeu tal trajeto entre maio de 1931 e fevereiro de 1933 , e que inaugura a pesquisa de campo como método entre os franceses. Ao término de cada dia, durante os dois anos da expedição, tudo o que o autor julgar relevante da perspectiva subjetiva é digno de ser registrado - seja um sonho, o calor que o incomoda, seus delírios eróticos, conversas com os colegas, ou dificuldades em lidar com os nativos. Como apresentá-lo em sua dimensão propriamente interna, uma vez que não defende tese alguma, senão sua própria obsessão pelo real, perseguido através de uma intransigência constante em revelá-lo a si mesmo, para que, assim, a objetividade seja desnudada? Ora, diante desta tarefa, a fidelidade de Leiris é inflexível, mesmo diante da consciência de que ela é inexeqüível: "Maldito diário (não importa o que eu faça, ele acabará não sendo inteiramente sincero)" ${ }^{8}$. Leiris faz as vezes de um sisifista moderno: está condenado eternamente a empurrar a pedra da subjetividade até o cume da exposição, apenas para, uma vez lá em cima, vê-la rolar morro abaixo, momento de retomar sua tarefa. Sendo assim, irei guiar minha leitura pelas quatro questões teóricas e metodológicas que Fernanda Peixoto, na apresentação do livro, julga fundamentais para uma reflexão sobre a etnografia 9 - entretanto, a partir desse mapa, a responsabilidadeé minha.

Começo pela questão do intervalo de tempo entre acontecimento e registro. Leiris empreende, durante o dia, as investigações etnográficas das quais está encarregado: as sociedades ditas secretas, ou seja, os ritos de iniciação, possessão, as evocações mágicas e religiosas. As informações correspondentes são organizadas em fichas, que compõem o arquivo da missão; dentre elas, o que Leiris julgou de relevante está, de alguma forma, no diário, inclusive transposto literalmente. trópicos de Lévi-Strauss e a África de Michel Leiris". Novos Estudos, nª 33 , 1992, pp.187-98.

[7] Leiris, M., A África fantasma, op. cit., p.30o.

[8]Ibidem, p. 647 .

[9]Peixoto, F., “Aviagem como...", op. cit., p. 20. 
[10] Leiris, M., A África fantasma, op. cit., p.111.

[11] Ibidem, p.118.

[12] Ibidem, p. 50 .
A redação do diário íntimo, como ele o denomina, geralmente é empreendida antes de se deitar, e apresenta, assim, os eventos e as digressões do dia. Por exemplo: "Na volta, visão de um pôr do sol magnífico, de pós-tornado, sobre a terra violeta-podre, de sapé e de couro molhados"10; ou: "O macaco, visto na natureza, perde inteiramente o caráter burlesco que assume quando enjaulado: seé gordo, torna-se o gnomo da floresta; se é magro, o duende" ${ }^{11}$. Tais apontamentos jamais serão reescritos, sendo publicados tais como foram registrados no calor do momento, ou até algumas horas depois.

Nesse sentido, é interessante pensar o que precede o livro: um preâmbulo de 1981, dois prefácios, de 1951 e 1934, e o prospecto da primeira edição - espécie de folheto publicitário então solto entre suas páginas. Em tais textos, Leiris repensa, em diversos momentos da vida, sua experiência africana dos anos 1930, mantendo, contudo, o diário intacto. As reflexões variam desde comentários sobre o título original do livro, a motivação da viagem, o que seria, para ele, a África antes da viagem e no momento em que escreve o preâmbulo, sua relação com a etnografia, o envelhecimento do livro (ou seria de seu autor?); passa por digressões rousseaunianas e nietzschianas, pela violência e chega à autocrítica de sua fuga e confissão, que resumem, a seus olhos, suaviagem pelo continentee a redação do diário - se o mundo pode ser transformado, lançar mão de uma confissão para justificar uma fuga é uma defesa frágil, assume ${ }^{12}$.

AÁfrica fantasma lida com a dificuldade de tradução da experiência vivida, reinterpretada no texto. Vive-se, a princípio, diante da empreitada de se redigir uma experiência passada, esta deve ser traduzida, percurso que tem duas implicações: primeiro, reviver a própria experiência, conferindo-lhe uma narrativa, o que, por conseguinte, pressupõe uma ordem; segundo, viver a própria experiência da tradução. Esse movimento opera múltiplas sobreposições de experiência e escrita, se se pensar no preâmbulo e nos prefácios que Leiris escreveu ao longo de sua vida. O que se vislumbra nesse processo, senão, e apenas vagamente, o próprio Leiris?

O diário levanta a reflexão sobre a redação de diários. Mas, acima de tudo, a escrita apresenta-se, para Leiris, como um caminho possível para a terapia psicanalítica: a cura através das palavras. Trata-se de um esforço de lidar com a violência do deslocamento radical que Leiris sente em relação à sociedade francesa, que se traduz, para ele, em obsessões cujos temas mais salientes selecionei. Primeiro, a morte:

Agora, estousó (hábem unsseismeses isto não meocorre, ao menosnessas condições) e penso no que faço aqui. Disfarce grosseiro para ocultar de mim mesmo meu terror persistente (e crescente) da morte, da velhice e mesmo da vida. A existência ascética que levo não me concede nenhum paraíso infantil. Ela não me purifica, não me fixa na liquefação putrefata da vida ${ }^{13}$. 
O sexo, o erotismo e o ritual:

Eu sempre vi o coito como um ato mais ou menos mágico, esperei de algumas mulheres o que se pode esperar dos oráculos, tratei as prostitutas como pitonisas... Eu também sempre penso na velha alcoviteira mística com respeito e afeição. Que pena não existir mais, em nossos dias e em nosso país, a prostituição ritual!14.

[14] Ibidem, p. 447.

E, enfim, os sonhos, que, em primeiro de agosto de 1931, por exemplo, ocupam por completo os registros do dia ${ }^{15}$.

Ao lidar diariamente com suas incessantes obsessões conforme se desloca no espaço, conseguiria Leiris suspender o tempo? Seria possível responder com uma afirmativa, uma vez que a escrita terapêutica de caráter psicanalítico busca a construção de uma mitologia individual, uma ordem narrativa que dê conta da experiência? Lembro que Claude Lévi-Strauss aponta o efeito de suspensão do tempo produzido pela dimensão mítica. Tal efeito, contudo, seria privilégio reservado ao diário e negado a Leiris durante seu trajeto? Questão difícil, se não impossível de ser respondida, já que a viagem pela África só persiste no livro, como narrativa que deseja dar conta de uma experiência dissolvida no tempo.

A experiência africana de Leiris, apesar de sobrecarregada por suas obsessões, também consiste em um exercício de descentramento, lançando-o em um limbo entre sua terra natal e os espaços que percorre, $\mathrm{O}$ que talvez também contribua para o efeito de tempo suspenso. $O$ fato é que, deslocado na França, coisa que o incita à África, ele se vê aqui na pele inalienável do estrangeiro. "Muito alegre, Emawayish alterna cantos zar e cantos profanos. Está tão animada que ela fala zar com as companheiras. Eu fico irritado, pois essa gíria, em sua boca, tem algo de impuro e me faz lembrar, mais um vez, que eu sou um estrangeiro"16. Não é irônico esse incômodo constante com sua própria identidade, que, apesar da extensa viagem, permanece caracterizada peculiarmente com a insígnia do deslocamento?

Tudo isso contribui, de modo decisivo, para que as pessoas com quem Leiris se depara ao longo da jornada se apresentem caricaturadas sob sua pena. Personagens caricatos no espaço íntimo entre o drama e a comédia - traço que se intensifica durante a estada na Abissínia, local onde a missão permanece por mais tempo, cerca de seis meses. Obcecado aí pelos ritos de possessão, Leiris desenvolve um fascínio erótico por Emawayish, pintada entre o desejo carnal e a subseqüente frustração, que cresce conforme a relação entre etnógrafo e autóctones vai desnudando os interesses subjacentes.

Pouco tempo depois, é Emawayish que se retira e boceja ruidosamente, como as mulheres invadidas pela possessão. "O kouragna me ataca", 
[17] Ibidem, p. 587 .

[18] Ibidem, p. 608 .

[19] Shakespeare, William. Hamlet. Harlow: Longman, 1968, II.ii.573579, p. 93 . ela diz. Provavelmente, o kouragna está com ciúmes da velha [Malkam Ayyahou ], que acaba de receber um presente tão suntuoso [um quadro]... Mal transcorre um minuto, Emawayish, com afeto, segura minhas mãos e, com voz baixa, me pede perfume. De repente, eu me sinto mais enojado do que com qualquer artimanha de puta. E, para mim, o dia acaba sobo signo desse gesto... ${ }^{17}$.

Outra figura caricata é Abba Jerônimo: "Além de ser tão pitoresco, tão rococó, tão decrépito, tão pouco humano! Quem poderia parecer mais 'intelectual' que um intelectual abissínio?"18.

Nessa empreitada modernista tão pouco usual — mas, insisto, modernista em sua busca pelo real —, a subjetividade de Leiris é, de fato, escancarada. Não toda ela, pois é impossível, como ele mesmo confessa. A experiência não se aloja na narrativa sem perda na tradução: o traço modernista marcante em Leiris é o esforço extenuante de objetivar sua subjetividade. Com isso, advém a falência de seu projeto: se sua subjetividade não pode ser exposta por completo, a objetividade tem suas linhas nubladas, dissolvidas nos limites das obsessões impronunciáveis do autor. Se a África é fantasmagórica para Leiris, este o é aos olhos do leitor, que, toda vez que tenta agarrá-lo, se vê de mãos vazias; Leiris parece se descortinar por inteiro apenas para, no instante seguinte, sem deixar vestígios, desaparecer. Tudo se passa como se o fantasma de Leiris pairasse, todos os dias, entre as páginas d'A África fantasma, em um incessante movimento de entrar e sair de cena que domina todo o livro, pois tudo que se lê provém de sua pena. Quem conheceu Brás Cubas, o defunto-autor, aprendeu a desconfiar do narrador; eu poderia, assim, refletir em uníssono com Hamlet, após este se deparar com o fantasma de seu pai:

The spirit that I have seen

May be the devil. And the devil hath power

T'assume a pleasing shape; yea, and perhaps

Out of my weakness and my melancholy,

As he is very potent with such spirits,

Abuses me to damn me. I'll have grounds

More relative than this ${ }^{19}$.

Mas Leiris também faz as vezes de Hamlet, já que sua marcaé aquela da digressão e da hesitação em agir; ou, ao menos, é isso que quer demonstrar. Leiris não hesita no momento de escrever seu diário: eis aqui um livro concebido como ato de escrever. Assim, o que permanece, sobretudo, é a escrita por si só. 
Carlo Ginzburg, diante dos incômodos oriundos da contraposição entre "racionalismo" "irracionalismo", tratou de explorar aemergência, em fins do século XIX, de um modelo epistemológico - chamado por ele de paradigma indiciário - no qual tal relação antípoda não tivesse lugar para se alojar. O paradigma indiciário se apóia na semiótica e sua emergência é discernível através de três personalidades contemporâneas e singulares: Sigmund Freud, Sherlock Holmes e o crítico de arte Giovanni Morelli."Nos três casos, pistas talvez infinitesimais permitem captar uma realidade mais profunda, de outra forma inatingível. Pistas: mais precisamente, sintomas (no caso de Freud), indícios (no caso de Sherlock Holmes), signos pictóricos (no caso de Morelli)"20. Em suma, trata-se de um saber que não permite formalização prévia: não é possível elencar regras que permitam identificar as pistas corretas; o processo todo repousa sobre uma técnica aprendida apenas na experiência.

Ao tomar a máxima de Ginzburg: "Se a realidade é opaca, existem zonas privilegiadas - sinais, indícios - que permitem decifrá-la" ${ }^{21}$, penso que se pode iniciar uma discussão sobre o método abdutivo em antropologia, em especial daquela que chamo aqui de modernista. Torna-se interessante, desse ponto de vista, esboçar uma breve comparação do livro de Leiris com um exemplar do cânone antropológico de sua época, tomando como parâmetro o tema da objetividade e da presença do autor no texto. Para tanto, a monografia de Edward EvansPritchard sobre os nuer me parece apropriada, devido ao seu caráter paradigmático22. Publicada seis anos após $A$ África fantasma, a célebre etnografia sobre os nuer é representativa do realismo etnográfico gênero monográfico inauguradoem 1922 por Bronislaw Malinowski ${ }^{23}$ e termo criado pela crítica norte-americana dita pós-moderna ${ }^{24}$. Seguindo a síntese das convenções desse gênero elaborada por Teresa Caldeira, pode-se dizer que se trata de uma estrutura seqüencial, na qual o antropólogo se afasta do texto, após se apresentar como autoridade no assunto devido a sua vivência in loco; o caráter de realidade é perseguido com detalhes da vida cotidiana que exibem o ponto de vista do nativo mediante a exegese de seus termos e conceitos. Sob essa apresentação, estrutura-se a visão de sociedades e culturas como unidades discretas totais, descritas através de uma abordagem metonímica no tempo presente ${ }^{25}$.

Leiris selocaliza em uma posição bem distinta daquela ocupada por Evans-Pritchard, pois, se este, caracteristicamente, submete os fatos à teoria, aquele, além de não compartilhar das convenções do realismo etnográfico, sobrepõe a escrita à experiência. Evans-Pritchard quer se dissolver no texto, alegando, para tanto, sua autoridade; Leiris pretende se revelar no texto, e sua autoridade não inclui nem a si mesmo.
[20] Ginzburg, Carlo. "Sinais - Raízes de um paradigma indiciário". In: Mitos, emblemas, sinais - Morfologia e história. São Paulo: Companhia das Letras, 2007,pp.143-79, p.150.

[21] Ibidem, p.177.
[22] Evans-Pritchard,Edward.Os nuer - Uma descrição do modo de subsistência e das instituições politicas de um povo nilota. São Paulo: Perspectiva, 1978.

[23] Malinowski,Bronislaw.Argonautas do Pacífico Ocidental - Um relato do empreendimento e da aventura dos nativos nosarquipélagosdaNovaGuinéMelanésia. São Paulo:Abril Cultural,1984.

[24] Cf. Clifford, James e Marcus, George (orgs.). Writing culture - The poetics and politics of ethnography. Berkeley: University of California Press, 1986; e também Clifford, J. The predicament of culture - Twentiethcentury ethnography, literature, and art. Cambridge, Massachusetts: Harvard University Press, 1988.

[25] Caldeira, Teresa. "A presença do autor e a pós-modernidade em an-

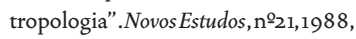
pp. 133-57. 
[26] Leiris, M. A África fantasma, op. cit., p. 105.

[27]Clifford, J. "Sobre o surrealismo etnográfico". In: A experiência etnográfica-Antropologia e literatura no século $X X$. Rio de Janeiro: Editora UFRJ, 2002, pp.132-78, pp.167-68.

[28] Ibidem, p. 169 .

[29] Modell, Judith. "It is besides a pleasant english word - Ruth Benedict's concept of patterns". Anthropological Quarterly, vol. 62, $\mathrm{n}^{\mathrm{Q}}{ }_{1}$, 1989, pp. 27-40.

[30] Eliot, T. S. "A terra desolada". In: Poesia.Rio de Janeiro: Nova Fronteira, 2006, pp. 97-127, p.119.

[31] Frazer, sir James G. O ramo de ouro. São Paulo: Círculo do Livro, 1982.
No entanto, ambos perseguem a realidade através de pistas: o inglês, atento aos sinais de seu povo-objeto; o francês, perturbado por sinais de sua própria psique - os dois se lançam na tentativa de, por meio de sinais abduzidos de seu contexto vivido, reconstituir uma totalidade. Escreveu Leiris em 16 de julho de 1931:

Sob o rochedo, recolhemos uma corda: cabresto de carneiro que, todos os anos, na mesma época, é sacrificado aos jacarés, de que, dizem os guias, o poço está cheio. A descoberta deste pedaço de corda me enche de alegria, pois começo a entrever o que há de apaixonante na pesquisa científica: ir de elemento de prova a elemento de prova, de enigma a enigma, perseguir a verdade como a uma pista... ${ }^{26}$.

Teria Leiris vislumbrado aí um caminho para se perseguir e se encontrar, empreendendo uma etnografia de si mesmo?

\section{IV}

James Clifford aponta $A$ África fantasma como o único exemplo puro de etnografia surrealista, isto é, o procedimento pelo qual o artista-escritor coleta elementos reais para depois estabelecer uma montagem. Qualquermensagemsemióticaécompostadessamaneira, mas, nolivro de Leiris, o próprio procedimento é a mensagem: as suturas, incongruências e pistas são todas justapostas no decorrer dos dias, abandonadas em exposição, sem uma organização homogênea. $O$ conhecimento etnográfico é exposto de forma crua e não há intenção em apresentar totalidade cultural alguma ${ }^{27}$ : "Mas todo etnógrafo não é um pouco surrealista, um reinventor e um 'recombinador' de realidades?" 28 .

A articulação entre antropologia e arteéum espaço prolífico.Judith Modell mostrou como Ruth Benedict incorporou ao termo "padrão" conotações estéticas que proveram uma agenda específica para estudar culturas, tratando-as como arte e acessando-as através de critérios definidos com base nos princípios dominantes na literatura e na arte da década de $1920^{29}$. O caminho inverso também foi percorrido. T.S. Eliot, em nota ao seu poema "A terra desolada"30, aponta seu imenso débito para com Oramo de ouro, de sir James George Frazer, obra enciclopédica que teve, em sua época, uma repercussão além do espaço acadêmico poucas vezes alcançada por um trabalho antropológico ${ }^{31}$. A África fantasma talvez seja raríssima no sentido de fundir as duas dimensões: etnografia e literatura, sendo que esta última se sobrepõe porque amplifica o caráter de escrita daquela.

Seguindo para a conclusão, gostaria, ainda, de me enveredar por uma digressão da face artística do diário de Leiris. Em uma passagem famosa, Lévi-Strauss aponta como a arte se mantém, no Ocidente, 
como um espaço protegido para o pensamento selvagem ${ }^{32}$.A arte, para ele, estaria a meio caminho entre o conhecimento científico e o pensamento mítico; o artista funde, dessa maneira, o cientista e o bricoleur: “[...] com meios artesanais, ele elabora um objeto material que é também um objeto de conhecimento"33. A partir daí faz-se três distinções. Primeiro, cientista e bricoleur se diferenciam na medida em que o primeiro muda o mundo por meio de estruturas, ao passo que o segundo cria estruturas por meio de fatos. Segundo, a arte parte de um conjunto formado por objeto e fato e segue em direção à descoberta de sua estrutura, enquanto "[...] o mito parte de uma estrutura por meio da qual empreende a construção de um conjunto (objeto + fato)"34. Terceiro, há uma analogia entre o pensamento mítico no plano especulativo e o bricolage no plano prático 35 . A posição da arte, então, é eqüidistante da ciência, do pensamento mítico e do bricolage - o que comporia um triedro cujo vértice seria ocupado pela arte.

Creio que AÁfrica fantasma se aloja nesse vértice artístico, incorporando as relações descritas entreos outros vértices, que formam as faces do triedro. Em outras palavras, haveria quatro Leiris: o Leiris-cientista, explorando em campo uma tarefa etnográfica; o Leiris-bricoleur, que se apropria de fatos fragmentados e os organiza em uma colagem, estrutura na qual os elementos estão dispostos em justaposição; o Leirismítico, construtor de uma narrativa pessoal ao fim da qual reside uma suposta cura para seu sentimento de deslocamento; enfim, o Leirisartista, avatar que se sobrepõe aos outros talvez por ser sua matriz identitária, isto é, o escritor. A fantasmagoria de Leiris advém do fato de que nenhuma de suas versões é inteligível ao se perder de perspectiva as outras; a sobreposição do escritor é a mais palpável delas, mas se torna oca sem suas variantes.

AÁfrica fantasma, então, está estruturada no duplo jogo metonímico e metafórico.Adimensão metonímica avança com a análise dos fatos ao passar dos dias, sem que nenhum deles se sobreponha aos demais, permitindo que cada um represente o todo; o plano metafórico se delineia no fato de que a fantasmagoria de Leiris é a sua escrita, de modo que, entre a experiência africana e o próprio Leiris, interponha-se a mediação sintética, ou seja, o diário. AÁfricafantasmaéo pensamento selvagem ou, talvez, o pensamento em estado selvagem - de Michel Leiris.

Lembro, enfim, de Michel Foucault:

Não que a palavra seja imperfeita e esteja, em face do visivel, num déficit que emvão se esforçaria porrecuperar. São irredutiveis umao outro: pormais que se diga o que se vê, o que se vê não se aloja jamais no que se diz, e por mais que se faça ver o que se está dizendo por imagens, metáforas, comparações, o lugar onde estas resplandecem não é aquele que os olhos descortinam, mas aquele que as sucessões da sintaxe definem ${ }^{36}$.
[32]Lévi-Strauss, Claude. O pensamento selvagem. Campinas: Papirus, 2005 , p. 245.

[33] Ibidem, p. 38 .

[34] Ibidem, p. 41.

[35] Ibidem, pp. 38-46.
[36] Foucault, Michel.As palavrase as coisas - Uma arqueologia das ciências humanas. São Paulo: Martins Fontes, 1999 , p. 12.

[37] Jamin, J. "Introduction à Miroir de l'Afrique". In: Leiris, M. Miroir de l'Afrique, op. cit., pp. 9-59, pp. 56-57.

[38]Além da coletânea Miroir de l'Afrique, op. cit., e dos outros dois títu- 
los publicados no Brasil (cf. nota 4), uma bibliografia introdutória acerca de Leiris e sua obra inclui a biografia escrita por Aliette Armel (Michel Leiris. Paris:Fayard,1997) e a entrevista realizada por Jean Jamin e Sally Price poucos anos antes do falecimento de Leiris: "A conversation with Michel Leiris". Current Anthropology, vol. 29, n- ${ }^{\circ}$ 1, 1988, pp. 157-74; em francês, publicada como C'est-à-dire-Entretien avec Jean Jamin et Sally Price, suivi de Titres et Travaux. Paris: Jean-Michel Place, 1992.
Retorno, assim, ao excerto de Moby Dick que Leiris gostava de citare que, de acordo com Jean Jamin, serve de alegoria para pensar o próprio Leiris 37 . As tatuagens de Queequeg são a alegoria do conhecimento marcada na concretude do corpo: aqui, o pensamento se faz nos signos em si mesmos, em um redobramento da relação entre as palavras e as coisas. O caráter representativo do signo está, sem dúvida, presente como ícone; mas a ele se sobrepõe o fato de que, se representados em seu corpo, tais signos são o próprio Queequeg ${ }^{38}$.

LUÍs FELIPE SOBRAL é mestrando em Antropologia Social pela Unicamp e bolsista do CNPq. 